\title{
Fostering Learners Adaptive Competence: Does Acquisition of Self-Regulation and Metacognition Differentiate between Students?
}

\author{
Stephen Ntim (PhD; M.Phil. M.A; B.Ed.) \\ Faculty of Education \\ Catholic University of Ghana \\ P.O. BOX 363, Sunyani, B/A \\ Ghana
}

\begin{abstract}
This study examined whether or not heuristics skills such as self-regulated and metacognitive strategies differentiate significantly between high ability students. Using an experiment with purposive sample size of estimated two hundred and forty high ability students, an independent t-test conducted at alpha 0.01 suggested a high statistical difference between the experimental and control groups performed at $[t=2.91, p=0.01]$. This was suggestive that the control group without the self-regulated and metacognitive intervention strategies performed much lower than the experimental groups. These results were interpreted that it was the acquisition of these skills that was the predicting cause of this enhanced performance of the experimental group as opposed to the control. Self-regulated and metacognitive skills significantly fostered this adaptive competence of learners exposed to these strategies more than those who were not.
\end{abstract}

Keywords: adaptive competency; self-regulation; metacognition; heuristic methods.

\section{Introduction}

Education in the $21^{\text {st }}$ century focuses on enhancing the skill to transfer knowledge and skills acquired in the classroom in different situations. This is referred to as 'adaptive competence' (AC). .Globally it is estimated that on the average only 6\% of adult population are capable of demonstrating some level of high proficiency in solving problems in the contemporary economy, which is increasingly highly technological (http://widgets.weforum.org/nve-2015/chapter1.html; (Organization for Economic Co-operation and Development. 2013). This means employability in today's economy driven by such skills as innovation, critical thinking, problem solving, etc. human resource needs a blend of skills that is transferable in multiplicity of contexts. Two decades ago, European industrialists (1995) identified key characteristics of what contemporary learning needs to focus 
on if academic learning in the schools is to commensurate with the requirements of contemporary human resource needs.

This shift in skill demand indicates that an average of one third of companies around the globe had challenges filling vacant positions in 2014 as a result of few people with relevant skills (Manpower Group, 2014). Similarly, a survey in 24 countries showed $16 \%$ of adults with poor literacy proficiency as well as $19 \%$ with low proficiency in numeracy. Only $6 \%$ of adults showed some high level of 'problem-solving' proficiency in highly developed technology environments (OECD Skills Outlook, 2013).

\section{Statement of Problem}

With this as background, it is critical that education at all levels, especially teaching and learning focus more than before to develop in students/pupils, the ability and the skills to foster adaptive competence, so that learners can transfer skills and knowledge in varied contexts. Acquiring these helps the learner to acquire both the willingness, as well as the skill to change fundamental competencies flexibly (Bransford et al., 2006; DeCorte, 2007; Hatano \& Oura, 2003). Regardless of the importance of developing adaptive competence skills, not much scientific work has been conducted in many geo-political areas in Africa. Instruction designed to foster heuristic skills in students still remains minimal in research literature. The findings of this paper will bridge this gap. Secondly, research evidence on adaptive competence (AC) indicates among others the following: a) deficient students/pupils performance in problem solving and /or analytical reasoning; b) lack of a coherent and flexible domainspecific knowledge; c) absence of heuristics methods; d) poor metacognitive knowledge; f) deficient cognitive self-regulation; f) minimal positive affect. Therefore, mastering these skills through effective instruction is predicted to result in better performance (Brown \& Palincsar, 1989; De Corte, Verschaffel \& Masui, 2004). Given the fact that contemporary construct of learning is more productive and essentially skill building (De Corte, 2010; Kirby \& Lawson, 2012; National Research Council, 2000, 2005), it is imperative to conduct this study to contribute to the available literature.

\section{Research Questions}

Following from the above identified problem, this study sought to find answers to the subsequent three (3) pedagogical questions on heuristics, cognitive strategies and self-regulation:

1) What heuristics methods are likely to increase learners' probability of finding correct solutions to isomorphic problems?

2) In what ways, can instruction/ pedagogy develop learners' cognitive strategies?

3) What pedagogical/instructional strategies are likely to aid learners to regulate their cognitive processes? 
Significance of study

Many developing nations especially in Sub-Sahara Africa continue to invest in formal education. In Ghana for example, an estimated $40 \%-50 \%$ of annual budgetary allocation is earmarked for education (http:// multinewsonline.com/economy/2017/04/education-budget-jumps-byghc1bn-in-2017/).This notwithstanding, Ghana still has a high level of unemployed graduates. The National Council for Tertiary Education (NCTE) continues to highlight the blending of higher education skills with national development. Recommendation to support tertiary institutions to train the nation's human resource needs with the demands of industries has been made. The findings of this paper therefore would constitute an invaluable resource to all stakeholders.

\section{Literature/Theoretical framework}

To minimize the limitations of the traditional mode of teaching and learning that fails to account for social and contextual factors needed in today's labour market, contemporary school learning must do more. Contemporary construct of learning that is productive and likely to enhance adaptive competence has the following core attributes: active/constructive, self-regulated, situated, collaborative, goaldirected, student diversity oriented and essentially skill building (De Corte, 2010; Kirby \& Lawson, 2012; National Research Council, 2000, 2005). Based on this, the following review of literature is built along the following themes: a) learning as constructive, b) learning as self-regulated, c) learning as situated and collaborative, d) building on learners' prerequisite knowledge, and e) student diversity.

Learning as Constructive/Dewey's Epistemological Construct

Viewing learning as constructive is topical among educational psychologists (Aljohani, 2017; Simons, van der Linden, \& Duffy, 2000). The term makes reference to the idea that in learning, it is the subjects' 1 who actively construct their own knowledge. Constructing meaning is learning. Two implications could be derived from this: a) focus should be on the learner as he/she constructs meaning (rather than focusing on the content or the lesson); b) every knowledge is meaning-dependent and experiential and this experience is constructed by the learner. Learners are perceived as actively engaged in constructing knowledge by a reorganization of their previous mental structures. Thus, engaging involvement that students bring to the process of acquiring knowledge and skill is critical (Aljohani, 2017). Ample evidence supports constructive learning with earlier works such as Bruner (1961) and Piaget (1955).

Philosophically, constructive learning has the same fundamental ideas of Dewey's epistemology that learning means individuals constructing meanings. The following are some of the principles of the constructivist view of learning: a) Learning is an engaging/active process. Through this, the subject makes active use of the senses and constructs meaning out of the sense experience (Dewey, 1916); b) People learn to learn as they learn: this means learning has two forms: i) the construction of signification (meaning), and ii) constructing meaning out of systems of meaning; c) Meaning construction takes place in the mind. Activities 
engaging both mind and hands need to be provided (Amineh \& Asl, 2015; Henrique, 1990). Dewey called this 'reflective activity'; d) There is a link between language and learning in constructive learning: the language we use largely has impact on learning and this is supported by empirical evidence (Vygosky, 1962); e) Learning is directly related to, and associated with social activity with people we come into contact with, especially significant others, which include teachers, parents, peers etc. This is because humans fundamentally construct knowledge and thinking from culture, especially through social activities such as language, discourse, etc. (Edwards \& Mercer, 1987); f) Humans learn when new ideas combine with what they already know as well as what they belief including their prejudices and biases. Learning is inseparable from our lives (Cole \& Griffin, 1987); g) Learning is enhanced when incoming knowledge is assimilated to already encoded and stored knowledge. The more we know, the more we can learn. Consequently, teaching and learning is facilitated, when teacher makes connection to the learner's prerequisite knowledge (Resnick, 1987: Resnick \& Klpofer, 1989); h) Learning is gradual and cumulative. This cannot happen instantaneously. Learning then is mastered and consolidated through repeated exposure and thought (Klpofer, 1989); i) Motivation is key learning principle under constructivist learning. Unless students know the reason of why they need to learn, they may not be engaged in using and applying knowledge and skills acquired from the classrooms (Resnick \& Klpofer, 1989).

\section{Self-regulated learning}

Learning is self-regulated when students are actively involved in learning on their own and become metacognitively, motivationally and behaviorally engaged. When students can monitor their mental processes such as attention allocation, strategies for remembering important and salient points, internally develop a high level of motivation for learning etc., these go a long way to enhance lifelong learning (Abadikhah et al, 2018; Cetin, 2015; Zimmermann, 1994). Effective self-regulated learners are likely to possess such learning strategies as consciously setting their goals for learning, making decision on strategies that would work, planning efficient use of time, ensuring good organization and efficient prioritization of both materials and information, flexibly shifting approaches monitoring their learning through performance feedback and making relevant adjustments in learning (Butler \& Winne, 1995; Meltzer, 2007; Puustinen \& Pulkkinen, 2001; Winne, 1995; Zimmerman, 1989, 2001). Besides, self-regulation has strong correlation with high academic achievement across different disciplines (Zimmerman \& Risemberg, 1997). Research evidence suggests that acquiring self-regulation is not spontaneous, but takes considerable time, and that self-regulation in learning as a feature of productive learning and adaptive competence needs to be encouraged from early childhood education (De Corte et al 2011).

Theoretically, self-regulated learning has been discussed from many epistemological perspectives. Developmentally, it has been perceived from social cognitive perspective. Implication is that intellectual development and social functioning are interrelated (Biemiller, Shany, Inglis \&Meichenbaum, 1998; Zimmerman \& Kitsantas, 2005). Knowledge therefore is seen to have a social 
dimension and is socially constructed (Bandura, 1999). This developmental perspective of self-regulation in learning means that self-regulative learning abilities are gradually developed across the life span (Bakracevic, Vukman, \& Licardo, 2010). Competence in self-regulation is assumed to have its origins initially from social sources, before it gradually becomes manifest within an individual, similar to the idea of apprenticeship (Beishuizen \& Steffens, 2011; Collins, Brown \& Newman, 1989).

A four-step process of self-regulation from the perspective of development has been proposed by Zimmerman and Kitsantas (2005). First, leaners acquire skills and strategies of self-regulation through the observation from social sources. Second, is the internalization of the strategy. Third, when the learner acquires the ability to apply strategy on his/her own. Fourth stage suggested by Zimmerman and Kitsanata (2005) is when learners are able to apply self-regulatory competence in higher order levels in variety of contexts. (Beishuizen \& Steffens, 2011). The motivating force here as suggested by Brofenbrenner $(1979,2005)$ has to do with relationships existing in a person's microsystem. The underlying assumption is that teachers and parental figures ensure that the relationships in the microsystem are activated (Schunk \& Zimmerman, 1997; Zimmerman, 1998). Lifelong learning of students is predicted on teachers' ability to enhance selfregulated learning through various classroom interventions (Kostons, van Gog \& Paas, 2011; Miller, Heafner \& Massey, 2009; Ness \& Middleton, 2011; Tonks \& Taboada, 2011)

\section{Learning as Situated and Collaborative}

Learning as constructive and self-regulated is linked to situated learning in the sense that neither of the two could take place without being situated in a context. Indeed it is in situated socio-cultural milieu where these learnings become embedded. (Kirshner \& Whitson, 1997; National Research Council, 2000). This perspective emphasizes that learning takes place principally through interaction in, and also through participating in sociocultural activities. Learning is distributed among variety of groups including the individual, the persons in the learning environment as well as resources such as technology and tools (Salomon, 1993).Parents understandably are the assumed core agents to develop and influence the academic and the psychosocial development (Abar, Carter \& Winsler, 2009; Maccoby \& Martin, 1983; Purdie, Carroll, \& Roche, 2004; Steinberg, Lamborn, Darling, Mounts, \& Dornbusch, 1994). Among young adolescents for example, self-regularity behavior is predicted to be more connected to high parental involvement (Purdie et al, 2004) and on their peers during midadolescents (Brown \& Larson, 2009). The potential of peers to significantly influence friends' motivation for learning is high (Altermatt \& Pomerantz, 2003; Berndt \& Keefe, 1995; Jones, Estell, \& Alexander, 2008).

\section{Building on learners' prerequisite knowledge}

Theoretical as well as empirical findings show that learners' previous knowledge is crucial in acquiring new learning tasks (Kalyuag, Chandler \& Swellerr, 2001; Shapiro, 2004; Weinert \& Helmke, 1998). Similarly, with respect to collaborative learning, the background knowledge that learners bring on board is found to be 
crucial in group learning (Cohen, 1994). Investigating the impact of previous knowledge in collaborative learning for example, O'Donnell and Dansereau (2000) showed that its influence is enormous. What this means is that previous knowledge can affect the findings in respect of collaborative knowledge (Ertl, Kopp \& Mandl, 2005; Ertl \& Mandl, 2006).

During pedagogical intervention when this background preconceptions (some of which could also be faulty) are not engaged, students may not only fail to understand new concepts taught, but could learn these new concepts simply for test purpose and therefore fail to apply them outside of the classroom. Empirical findings in early childhood education suggest a link between early childhood and meaning making. (Wellman, 1990). These early understandings constitute the bedrock for the building and integration of new knowledge, even though in some cases these initial understandings could be inaccurate (Carey \& Gelma, 1991). This inaccuracy could be exhibited whether in science or in the humanities (Gardner, 1991). As a result of this, effective teaching is one characterized to elicit from students prior understanding of new task to be taught. To develop competency in inquiry, teaching needs to emphasize three things to students: a) in-depth foundation of factual knowledge; b) facts and notions need to be understood within a conceptual framework and c) students need to have way of organizing knowledge that facilitates retrieval and application. Research studies comparing novice and experts performance show that ability to recognize patterns, make inferences to draw analogies to other problems appears to be closely related to experts than it is with novices. (Chi, Feltovich, \&. Glaser 1981). Thus, deep understanding of a subject is likely to transform factual information into usable knowledge. This is a socially embedded process. Teaching adapts to students prior knowledge in supporting (scaffolding) the learning of the less expert learners (Dunbar \& Fugelsang, 2005). Through this support, teacher helps students to bring theoretical understanding to a level higher than when there is no teacher guidance (Schwartz\& Fischer, 2004; Van der Steen, Steenbeek, Wielinski, \& Van Geert, 2012). This helps to co-construct knowledge with students (Azmitia \& Crowley, 2001).

Through the building of students' prior knowledge, they could also be helped to build meta-cognitive strategies which are critically important in fostering adaptive expertise. (Hatano \&Inagaki, 1986). Since these strategies are internal, and takes some time to develop compared to intellectual skills, the assumption is that learners would develop their own internal dialogue, which for most of the time are reflections of norms of culture and inquiry methods (Brice-Heath, 1981, 1983; Hutchins, 1995; Suina \& Smolkin, 1994). Empirical findings suggest that these strategies could be taught especially through reciprocal teaching (Palincsar \& Brown, 1984).

\section{Student diversity}

Individual differences in students is also a major determining factor in adaptive competence. Students do not perceive and process information in the same way (Shaw, 2012). A learning style indicates learners' response to a given learning task in terms of their perception and interaction to the task. (Keefe, 1988). These are 
not invariant. Learners adopt and adapt to different styles of learning relative to the subject matter and the learning task (Pritchard, 2009)

Students typically have one dominating learning style which they prefer to others. This can be activated by any learning task that matches with his/her preference. (Larkin \& Budny, 2005). Knowing students' preferred styles of learning can be helpful in guiding them. For example, Felder-Silverman (1988) presents a four dimension learning style consisting of the following: a) Perceiving: This could also be sensation or intuitive. It explains how students perceive information. Students who are more sensing tend to have preference for learning facts more easily with details, solving problems through established methods. Intuitive learners on the other have a tendency to prefer abstract concepts; b) Input (Visual or Verbal) makes distinction between learners on the basis of their preferred modes for presenting information. Whereas visual learners have a tendency to learn through the use of visual medium such as diagrams, images, etc., verbal learners on the other hand have a preference for either written or spoken materials. These two categories of learners learn best when pedagogical material is delivered by combining written forms, verbal and visual (Mills, Ayre, Hands, \& Carden, 2010); c) Processing (Active / Reflective) evaluates learners on how information is processed. Learners who are active have a preference to learn materials by using it, whereas reflective learners on the other hand, tend to reflect on how things work; d) Understanding: This could be either global or sequential. Generally it looks at how learners understand new information. Whereas learners who are sequential tend to follow a linear and molecular step-by-step approach with focus on links between different parts of the learning material, global learners on the other hand, prefer a more molar and global understanding before zeroing into details.

\section{Present Study}

The above literature suggests among others, that teaching to foster adaptive competence in learners is critically linked to the social and cultural contexts. Understanding is generally shaped through interaction with social agents. This social dimension of learning means that learners must be helped to acquire adaptive competences, such as the skill to flexibly apply, expand and change their acquired knowledge in variety of contexts to new learning tasks, as well as to lifelong learning. With this background, this present study makes the hypothesis that learners' adaptive competency is facilitated when teaching /learning makes connection, not just with the state of learners, but also facilitating self-regularity habits and metacognitive strategies of leaners. Therefore, experimental group with the same intellectual high ability as the controlled group exposed to teaching emphasizing heuristics strategies, should significantly perform better than the latter who were not exposed to such strategies. Consequently, this study measured the following variables on selfregularity: self-regulation, organizing, transforming, goal-setting and planning, rehearsing and memorizing and three variables on metacognition: declarative knowledge, procedural knowledge and conditional knowledge. 


\section{Methodology}

\section{Sample}

An estimated random purposive sample of two hundred and forty (240) second year students from four Ghanaian Senior High Schools participated in this study. Students' age ranged between 15-18 years. To avoid extraneous variables, such as family background, higher ability, etc. influencing the outcome of this study, students selected were from the same middle class urban parental background. Many of the parents were from the civil service. The academic ability of these students ranged between 3.45-3.56 of cumulative grade point average (CGPA). All participants had English as their second language in addition to Ghanaian language.

\section{Design and Materials}

In terms of experimental design, this study used an initial test to measure their over-all cognitive abilities to ensure similarity in cognitive abilities in addition to their cumulative grade points average (CGPA) from their academic records, before the 12-week didactical intervention. Using a variant of the Woodcock Johnson Test Guide (2017), their over-all cognitive abilities were measured on the subsequent variables: a) comprehension knowledge; and b) fluid reasoning ability. Two subtests were tested under comprehension knowledge, namely, i) verbal comprehension and ii) general comprehension. Under fluid reasoning, two tests were taken: i) concept formation and ii) analysis synthesis. The results of this initial test are indicated in Table 1. Additionally, the study also used a variant of the self-regulated learning interview schedule (SRLIS) (Zimmerman \& MartinezPons (1986) and adapted version based on metacognitive awareness inventory (MAI; Schraw \& Dennison, 1994) on self-structured metacognitive guide for the 12-week instructional intervention for the experimental group. These students were grouped randomly into two groups of experimental and control for twelve (12 weeks) in social studies class.

The experimental group was exposed to pedagogical intervention with emphasis on self-regularity habits and metacognition strategies in learning. The selfregularity habits included the following four variables: a) self-evaluation; $b$ ) organizing and transforming; c) goal-setting and planning; d) rehearsing and memorizing. The metacognitive strategies focused on helping students to recognize the different kinds of knowledge: declarative knowledge, procedural knowledge and conditional knowledge. For example, in self-evaluation, students were taught how to initiate ways of evaluating and assessing the quality and progress of their studies in social studies for the Term, such as: Do I regularly check over my homework to ensure that they are done properly? Do I relate the topic I am reading to real life situation? Under organizing and transforming, students were taught to ensure that they initiated on their own, a re-arrangement of the materials they are learning as means to improve their learning, such as making an outline of the main topics before writing a paper on the topics.

In goal setting and planning, students were taught how to initiate educational goals on their own and sub goals, as well as planning to ensure sequencing of prerequisite and time setting in relation to goals, such as studying three weeks 
before examinations and giving myself enough time. In rehearsing and memorizing, students were taught how to practise remembering what they have learned by categorizing topics into categories. The metacognitive strategies taught students the three categories of knowledge: declarative knowledge, procedural knowledge and conditional knowledge. Declarative knowledge focused on information or resources to perform a given task or about the demands of a task, that is, the resources or steps needed to solve a problem or a task as well as the nature of the task (what kind of a given task is related to this). Procedural knowledge as used in metacognition has to do with the mental mindset that one has about one's capability or belief that one has about oneself regarding the given task. It also involves an individual's self-perception of his/her capacity to do something. Conditional knowledge has to do with the knowledge one has regarding when, how, and why to use certain strategies to solve problems or answer questions. It refers to knowledge of specific situations, whereby students may use such subject-specific skills as algorithms, techniques and methods. The control group were given direct teaching without any of the above self-regulated and metacognitive strategies during the 12-week intervention. The hypothesis that was tested was that given the 12-week exposure to self-regulation and metacognitive strategies, the experimental group should significantly perform higher than the control.

\section{Procedure}

\section{Experiment}

One week after the twelve (12) weeks of pedagogical intervention for the four hundred students in the selected schools, the experiment was undertaken at the same time in all the schools with the assistance of senior research assistants. In each school, both the experimental and control were given the same tests that demanded both self-regulatory and metacognitive skills (especially in fluid reasoning with focus on their ability for synthesis, analysis and evaluation as pretested before the didactical intervention) and to be able to answer the questions on each of the following topics: a) the Constitution, b) Democracy and Nation Building; c) promoting national socio-economic development; d) population growth and development. Five (5) sub-questions were asked under each topic making a total of 20 questions. Each question was scored by 5 points making an aggregate score of one hundred (100) Each of the question included testing the ability of students beyond what they have learnt in the classroom, as well as asking them to explain the reasons for their answers.

For example, under Constitution, students were tasked to discuss the link between the separation of powers in the three branches of government as stipulated and how that relates to the freedom of the Judiciary. They were asked: a) to explain why the Constitution makes such provision; b) how this provision enhances the autonomy of the Judiciary; c) to explain the reasons for their answers. All the 20 questions had similar types of questions that demanded not just simply supplying an answer, but to find out why and how student arrived at their answers. All the scores of the two groups were computed into mean scores and standard deviations. 


\section{Results}

Table 1: Descriptive Statistics for Pre-test for experimental and control groups on verbal comprehension, general comprehension, concept formation and analysis synthesis

\begin{tabular}{|c|c|c|c|c|c|}
\hline & & $\mathrm{N}$ & Mean & $\begin{array}{c}\text { Std. } \\
\text { Deviation }\end{array}$ & $\begin{array}{l}\text { Std. Error } \\
\text { Mean }\end{array}$ \\
\hline \multirow{2}{*}{$\begin{array}{l}\text { Score on verbal } \\
\text { comprehension }\end{array}$} & Experimental & 120 & 16.60 & 3.56 & 0.563 \\
\hline & Control & 120 & 16.58 & 3.55 & 0.448 \\
\hline \multirow{2}{*}{$\begin{array}{l}\text { Scores obtained on general } \\
\text { comprehension }\end{array}$} & Experimental & 120 & 16.15 & 4. 04 & 0.633 \\
\hline & Control & 120 & 16.17 & 4.06 & 0.468 \\
\hline \multirow{2}{*}{$\begin{array}{l}\text { Scores obtained on concept } \\
\text { formation }\end{array}$} & Experimental & 120 & 15.68 & 3.59 & 0.569 \\
\hline & Control & 120 & 15.65 & 3.56 & 0.426 \\
\hline \multirow{2}{*}{$\begin{array}{l}\text { Score obtained on analysis } \\
\text { synthesis }\end{array}$} & Experimental & 120 & 16.35 & 3.51 & 0.482 \\
\hline & Control & 120 & 16.37 & 3.49 & 0.438 \\
\hline
\end{tabular}

Table 2: Descriptive statistics for Post-tests for experimental and control groups

\begin{tabular}{|c|c|c|c|c|c|}
\hline \multicolumn{2}{|c|}{ FORM TWO SECOND TERM SOCIAL STUDIES } & \multirow{2}{*}{$\mathrm{N}$} & \multirow{3}{*}{$\begin{array}{l}\text { Mean } \\
18.18\end{array}$} & \multirow{3}{*}{$\begin{array}{c}\begin{array}{c}\text { Std. } \\
\text { Deviation }\end{array} \\
3.47\end{array}$} & \multirow{3}{*}{$\begin{array}{c}\text { Std. } \\
\text { Error } \\
\text { Mean } \\
0.54\end{array}$} \\
\hline & & & & & \\
\hline Score on self-evaluation & Experimental & 120 & & & \\
\hline \multirow{3}{*}{$\begin{array}{l}\text { Scores obtained on organizing and } \\
\text { transforming }\end{array}$} & Control & 120 & 14.50 & 3.38 & 0.52 \\
\hline & Experimental & 120 & 17.38 & 3.21 & 0.51 \\
\hline & Control & 120 & 13.75 & 3.24 & 0.51 \\
\hline \multirow{2}{*}{$\begin{array}{l}\text { Scores obtained on declarative knowledge } \\
\text { questions }\end{array}$} & Experimental & 120 & 16.95 & 3.11 & 0.47 \\
\hline & Control & 120 & 13.10 & 2.97 & 0.45 \\
\hline \multirow{2}{*}{$\begin{array}{l}\text { Score obtained on procedural and } \\
\text { conditional knowledge questions }\end{array}$} & Experimental & 120 & 16.10 & 2.94 & 0.45 \\
\hline & Control & 120 & 12.32 & 2.36 & 0.36 \\
\hline
\end{tabular}


Table 3: Independent Samples t-test on scores obtained by experimental and control groups on the four variables

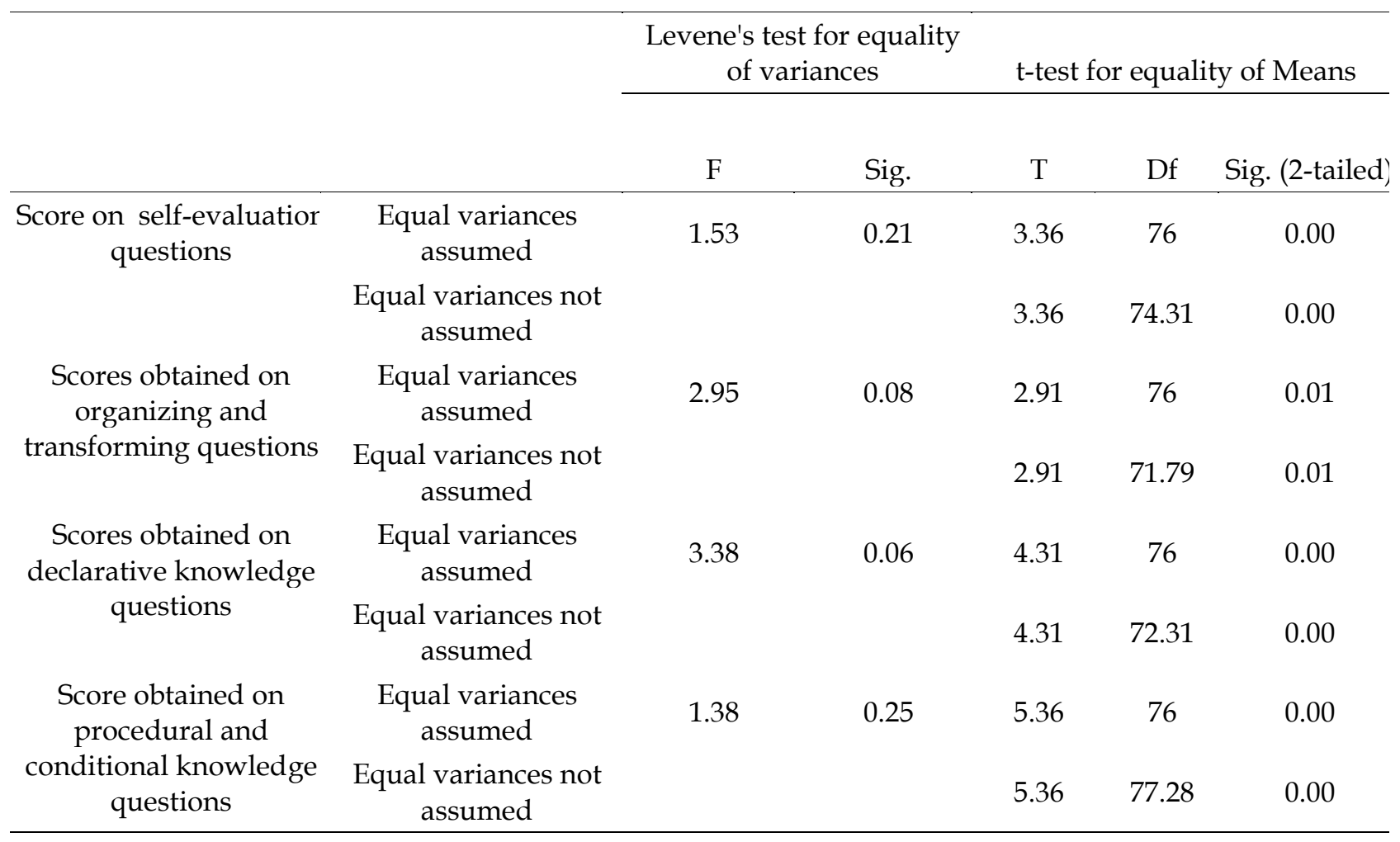

\section{Discussion}

The results as indicated in both the descriptive statistics and t-test above show that on all four variables, the experimental did better than the control. An independent t-test of samples was also conducted as in Table 2, to test whether differences in the mean scores were significant. Again the data as presented in Table 2 indicate that the control performed much lower than the experimental. The $t$-test at alpha $=0.01$ suggested a statistically significant difference between how the two groups performed $[t=2.91, p=0.01]$

These results of the two groups (both of who have higher academic ability) seem to suggest the influence of adaptive competencies, and the mastering of basic skills in self-regulated learning and metacognitive skills. These skills and competencies that the experimental group was exposed to, might have accounted for their better performance compared to the control. The fact that both students were asked questions that demanded going beyond what was asked, and were required to apply their knowledge before answering such questions, was an indication of acquiring the capacity to apply one's knowledge and skills to new learning situations. The findings as indicated in this study seem to corroborate large body of research suggesting the link between self-regulated and metacognitive components and enhanced students' performance skills (Brown \& Palincsar, 1989; De Corte, Verschaffel\& Masui, 2004). Additionally, the results seem to strengthen those studies in content-matter domain where novices 
perform poorly due to lack of mastery in adaptive competency (Garner, 1987; Schoenfeld 2016; Kyungil et al, 2011)

Again, the findings appear to strengthen those studies demonstrating deficiency of knowledge of fundamental concepts in domain-specific knowledge in the case of many students (Chi, Feltovich \& Glaser, 1981; De Corte, Greer, \& Verschaffel, 1996). It has been demonstrated in research findings that in the case of many pupils at the elementary level of education, there is the problem of misconceptions. Whereas people who have fundamental understanding of principles in domain specific areas tend to have grips of underlying principles, people who are less privy to fundamental understanding on the other hand, appear to have a preponderance towards focusing on superficial features. Given the fact that the two groups in this study were both high ability students, with cumulative grade point average ranging between 3.45-3.56, and yet after the 12week of pedagogical intervention, the control scored far less than the experimental group is suggestive of an executive control in the working memories of the experimental group. Thus, working memory executive control seemed to have facilitated the organization, guiding and the monitoring of learning and thinking processes more than it was in the control. In all the measures and the questions, the experimental group could successfully and simultaneously make intelligent inferences and elaborations in their answers many times more than the control. This was especially so on questions involving evaluations and monitoring. This implies that teaching to foster self-regulation and other heuristic skills, could be a predicting factor to enhance students' ability to transfer and apply knowledge and skills in variety of contexts, giving some support to the findings of Brown and Campione (1994).

The results in this paper also support the findings of research studies which examined students' self-regulatory competency and their learning adaptability in changing contexts such as Beishuizen and Steffens (2011), and the fourth stage in self-regulatory learning suggested by Zimmerman and Kitsanata (2005). Teaching and instruction in the classrooms, specifically designed to enhance students' selfregulatory and other heuristics skills continue to be the motivating force in developing these skills in students. The findings in this study show that fostering adaptive competency of students need to be consciously designed and taught. It cannot be taken for granted that the traditional way of topic-focused teaching, de facto can facilitate these skills, especially in the area of lifelong learning. It is in this respect that the data in this research also strengthen such studies as (Heafner \& Massey, 2009; Kostons, van Gog \& Paas, 2011; Miller, Ness \& Middleton, 2011; Tonks \& Taboada, 2011). Similarly, as demonstrated in this study, students could become metacognitive, when instruction explicitly teach them both the language, and the concept through a systematic knowledge construction approach that goes beyond one lesson or delivery. When self-adaptive competency is fostered this way, helping students to broaden and to expand their strategies of learning with new strategies that are more effective, they become effective learners and the data from this study confirm this position of Pintrich (2002) and Tanner (2012). 


\section{Implications for Classroom Intervention}

The first underlying pedagogical implication of the findings of this research for classroom intervention is that adaptive competency differentiates largely even between high ability students of the same range of cumulative grade point average. This means that heuristic skills that enhance students' mental flexibility and adaptability skills need to be consciously planned into the instructional designing. It should never be taken for granted that students, even high ability ones on their own can develop effective adaptive competencies outside of classroom interventions.

The second implication is that cognition is socially constructed. Therefore, even high ability students could carry some background preconceptions and misconceptions most of which could be faulty. Hence, if students are not engaged through interactive teaching with emphasis on enhancing self-regulatory and metacognitive skills, in which they are challenged to go beyond simply supplying answers and responding to questions, misconceptions and preconceptions could undermine their ability of grasping new concepts. This is especially so in elementary education, particularly childhood education. Since education is also essentially socially constructed, children and indeed adults develop fundamental understanding of issues and phenomenon from their social background. Some of these early social understandings constitute the bedrock for the building and the continuous integration of new knowledge. Therefore, if these prior concepts are faulty, it is constructive and self-regulatory learning that could provide the needed humus to correct cognition inaccuracies.

The third implication is that fostering adaptive competency is not unrelated to enhancing inquiry learning. Fostering inquiry learning in the classroom through constructive and self-regulated learning is crucially linked to the following three core areas in classroom intervention: a) teaching to ensure a deep foundation of factual knowledge of students; b) classroom intervention need to aim at ensuring that this factual knowledge is understood within a conceptual framework, and c) students need to have a way of organizing knowledge that facilitates retrieval and application. Each of these three core areas is facilitated when classroom interaction between teacher and student make varied connections and contexts between students' prior understanding and what they are being taught.

\section{Conclusion}

Classroom interventions consciously planned to foster adaptive competency of learners through constructive and self-regulated learning significantly differentiates between heuristic skills in experimental and control groups of high ability students. The findings of this study support those studies that formulate conceptual framework such as forethought, activation and planning as well as monitoring and activation in self-regulated learning. Additionally, the findings here suggest how classroom interventions could be fostered to enhance students becoming more engaged and involved in their own learning. Thus, when learners are taught to set goals for their own learning, learning becomes more constructive, active and engaging for them. Motivation becomes higher because students classroom behaviour is not only guided by the goals they set for 
themselves, but more importantly, these goals constrain their behaviour and therefore becoming more mentally active, engaged and focused.

\section{References}

Abar, B., Carter, K. L., \& Winsler, A. (2009). The effects of maternal parenting style and religious commitment on self-regulation, academic achievement, and risk behavior among African-American parochial college students. Journal of Adolescence, 32(2), 259-273. https:// doi.org/10.1016/j.adolescence.2008.03.008

Abadikhah, S., Aliyan, Z. \& Talebi, S. H. (2018). EFL students' attitudes towards selfregulated learning strategies in academic writing. Issues in Educational Research, 28(1), 1-17.

Aljohani, M. (2017). Principles of "Constructivism" in Foreign Language Teaching. Journal of Literature and Art Studies. 7 (1), 97-107. DOI:10.17265/2159$5836 / 2017.01 .013$

Altermatt, E. R., \& Pomerantz, E. M. (2003). The development of competence-related and motivational beliefs: An investigation of similarity and influence among friends. Journal of Educational Psychology, 95(1), 111. https://doi.org/10.1037//00220663.95.1.111

Amineh, R.J., \& Asl, H.D. (2015). Review of constructionism and social reconstruction. Journal of Social Sciences, Literature and Language, 1 (1) 9-16.

Azmitia, M., \& Crowley, K., The rhythms of scientific thinking: A study of collaboration in an earthquake microworld, In K. Crowley, C. D. Schunn, \& T. Okada, (Eds) Designing for science: Implications from everyday, classroom, and professional settings (pp. 51-82), NJ: Lawrence Erlbaum, Mahwah.

Bakracevic Vukman, K., \& Licardo, M (2010). How cognitive, metacognitive, motivational and emotional self-regulation influence school performance in adolescence and early adulthood. Educational Studies, 36 (3), 259-268. https://doi.org/10.1080/03055690903180376

Bandura, (1999). A social cognitive theory of personality. In L. Pervin \& O. John (Ed.), Handbook of personality (2nd ed., pp. 154-196).New York: Guilford Publications.

Beishuizen, J. \& Steffens, K. (2011). A conceptual framework for research on selfregulated learning. In R. Carneiro, P. Lefrere, K. Steffens, K. \& J. Underwood (Eds.), Self-regulated Learning in technology enhanced learning environments: A European perspective. Rotterdam: Sense Publishers https://doi.org/10.1007/97894-6091-654-0_1

Berndt, T. J., \& Keefe, K. (1995). Friends' influence on adolescents' adjustment to school. Child Development, 66(5), 1312-1329. https://doi.org/10.2307/1131649

Biemiller, A., Shany, M., Inglis, A., \& Meichenbaum, D. (1998). Factors influencing children's acquisition and demonstration of self-regulation on academic tasks. In D. Schunk, \& B. Zimmerman (Eds.), Self-regulated learning (pp. 203-224). London: The Guilford Press.

Bransford, J., Stevens, R., Schwartz, D., Meltzoff, A., Pea, R., Roschelle, J., Vye, N., Kuhl, P., Bell, P., Barron, B., Reeves, B., \& Sabelli, N.(2006). Learning theories and education: Toward a decade of synergy. In P. A. Alexander \& P. H. Winne Eds.), Handbook of educational psychology. (2nd. ed., pp. 209 - 244). Mahwah, J: Lawrence Erlbaum Associates. https:// doi.org/10.4324/9780203874790.ch10 
Brice-Heath, S (1983). Ways with words: Language, life and work in communities and classroom. Cambridge: Cambridge University Press. https://doi.org/10.1017/cbo9781139046206.009

Brice-Heath, S. (1981) Toward an ethnohistory of writing in America. In M.F. Whiteman (Ed.) Writing: The nature, development and teaching of written communication (Vol 1 pp25-45) Hillsdale, NJ: Erlbaum.

Brofenbrenner, U. (1979). The ecology of human development. Harvard: Havard University Press.

Brofenbrenner, U. (2005). Making human beings human: Bioecological perspectives on human development Harvard: Havard University Press.

Brown, A. L., \& Palincsar, A. S. (1989). Guided, cooperative learning and individual knowledge acquisition. In L. B. Resnick (Ed.), Knowing, learning and instruction: Essays in honor of Robert Glaser (pp. 393-451).Hillsdale, NJ: Erlbaum.

Brown, B. B., \& Larson, J. (2009). Peer relationships in adolescence Retrieved 29th May, 2018

from

https://onlinelibrary.wiley.com/doi/pdf/10.1002/9780470479193.adlps https:// doi.org/10.1002/9780470479193.adlpsy002004

Bruner, J. S. (1961). The act of discovery. Harvard Educational Review, 31, 21-32.

Butler, D. L., \& Winne, P. H. (1995). Feedback and self-regulated learning: A theoretical synthesis. Review of Educational Research, 65, https://doi.org/10.2307/1170684

Carey, S., \& R. Gelman (1991). The epigenesis of mind: Essays on biology and cognition. Hillsdale, NJ: Erlabuam.

Cetin, B. (2015). Academic motivation and self-regulated learning in predicting academic achievement in college. Journal of International Education Research, 11(2), 95-106.

Chi, M.T.H., P.J. Feltovich, \& R. Glaser (1981) Categorization and representation of physics problems by experts and novices. Cognitive Science 5:121-1 https://doi.org/10.1207/s15516709cog0502_2

Cohen, E. G. (1994). Restructuring the classroom: Conditions for productive small groups. Review of Educational Research, 64, 1-35. https://doi.org/10.3102/00346543064001001

Cole, M., \& P. Griffin, P (1987).Contextual factors in education. Madison, WI: Wisconsin Center for Educational Research.

Collins, A., Brown, J. S., \& Newman, S. E. (1989). Cognitive apprenticeship: Teaching the crafts of reading, writing, and mathematics. In L. B. Resnick (Ed.), Knowing, learning, and instruction: Essays in honor of Robert Glaser (pp. 453-494). https://doi.org/10.5840/thinking19888129

De Corte, E. (2007). Learning from instruction: The case of mathematics. Learning Inquiry, 1, 19-30. https:// doi.org/10.1007/s11519-007-0002-4

De Corte, E. (2010). Historical developments in the understanding of learning. In H. Dumont, D. Istance \& F. Benavides (Eds.). The nature of learning. Using research to inspire practice (pp. 35-67). Paris, FR: OECD Publishing. https://doi.org/10.1787/9789264086487-4-en

De Corte, E., Greer, B., \& Verschaffel, L. (1996). Mathematics teaching and learning. In D. C. Berliner \& R. C. Calfee (Eds.), Handbook of educational psychology (pp. 491-549). New York, NY, US: Macmillan Library 
De Corte, E., Verschaffel, L., \& Masui, C. (2004). The CLIA-model: A framework for designing powerful learning environments for thinking and problem solving. European Journal of Psychology of Education, 19, 365-384. https://doi.org/10.1007/bf03173216

De Corte, E., Mason, L., Depaepe, F., \& Verschaffel, L. (2011). Self-regulation of mathematical knowledge and skills. In B. J. Zimmerman, \& D. H. Schunk (Eds.), Handbook of self-regulation of learning and performance (pp. 155-172). New York: Routledge. https:// doi.org/10.4324/9780203839010.ch10

Dewey, J. (1916) Democracy and education. MacMillan, Dunbar, K. N. \& Fugelsang, J (2005). Scientific thinking and reasoning, In K. J. Holyoak \& R. G. Morrison, (Eds).Cambridge handbook of thinking and reasoning, (pp. 705-725), New York: Cambridge University Press, https://doi.org/10.1093/oxfordhb/9780199734689.013.0035

Edwards, D, \& Mercer, N. (1987). Common knowledge: The development of understanding in the classroom. London: Methuen, Erlbaum.

Ertl, B., \& Mandl, H. (2006). Effects of individual's prior knowledge on collaborative knowledge construction and individual learning outcomes in videoconferencing. In S. A. Barab, K. E. Hay \& D. T. Hickey (Eds.).Making a difference: The proceedings of the 7th International Conference of the Learning Sciences (ICLS) https:/ / doi.org/10.3115/1149293.1149312

Ertl, B., Kopp, B., \& Mandl, H. (2005). Effects of an individual's prior knowledge on collaborative knowledge construction and individual learning outcomes in videoconferencing. In T. Koschmann, D. Suthers \& C. Chan (Eds.), Computer supported collaborative learning 2005: the next 10 years! (pp. 145-154). Mahwah, NJ: Lawrence Erlbaum Associates

European Round-Table of Industrialists (ERT). (1995). Education for Europeans: Towards a learning society. Brussels, Belgium: ERT.

Felder, R. M., \& Silverman, L. K. (1988). Learning and teaching styles in engineering education. Engineering Education, 78(7), 674-681.

Garcia, T., \& Pintrich, P. R. (1995). Assessing Student's Motivation and Learning Strategies: The Motivated Strategies for Learning Questionnaire. Paper presented at the Annual Meeting of the American Educational Research Association, San Fransisco. https:/ / doi.org/10.1007/978-94-011-0657-3_12

Gardner, H (1991). The unschooled mind: How children think, and how schools should teach. Harvard: Basic Books

Hatano, G., \& K. Inagaki (1986). Two courses of expertise. In H. Stevenson, H. Azuma, \& K. Hakuta, (Eds). Child development and education in Japan, New York: W.H. Freeman.

Hatano, G., \& Oura, Y. (2003). Commentary: Reconceptualizing school learning using insight from expertise. Educational Researcher, 32, 26-29. https://doi.org/10.3102/0013189x032008026

Henriques, A., (1990). Experiments in teaching, In. Duckworth, E., Easley. J,. Hawkins, D \& Henriques, A.science education: A minds on approach to the elementary Years. Erlbaum,

Hutchins, E. (1995). Cognition in the wild. Cambridge, MA: MIT Press.

Jones, M. H., Estell, D. B., \& Alexander, J. M. (2008). Friends, classmates, and selfregulated learning: Discussions with peers inside and outside the classroom. 
Metacognition and Learning, 3(1), 1-15. https://doi.org/10.1007/s11409-007-90078

Kalyuga, S., Chandler, P., \& Sweller, J. (2001). Learner experience and efficiency of instructional guidance. Educational Psychology, 21, 5-23. https://doi.org/10.1080/01443410124681

Keefe, J. (1988). Profiling and utilizing learning style. NASSP Learning Style Series.

Kirby, J. R., \& Lawson, M. J. (2012). Enhancing the quality of learning: Dispositions, instruction, and learning processes. Cambridge, UK: Cambridge University Press.

Kirshner, D., \& Whitson, J. A. (Eds.). (1997). Situated cognition: Social, semiotic, and psychological perspectives. Mahwah, NJ: Lawrence Erlbaum Associates.

Kostons, D., van Gog, T. \& Paas, F. (2011). Training self-assessment and task-selection skills: A cognitive approach to improving self-regulated learning. Learning and Instruction, 22, 121- 132. https:// doi.org/10.1016/j.learninstruc.2011.08.004

Kyungil, K., Jinhee, B., Myung-Woo, N., \& Chang H. L. (2011) Do experts and novices differ? Relation versus attribute and thinking versus feeling in language use. Psychology Aesthetics Creativity and the Arts 5(4):379-388. DOI: 10.1037/a0024748

Larkin, T., \& Budny, D. (2005). Learning styles in the classroom: approaches to enhance student motivation and learning 2005 6th International Conference on Information Technology Based Higher Education and Training. https://doi.org/10.1109/ithet.2005.1560310

Maccoby, E. E., \& Martin, J. A. (1983). Socialization in the context of the family: Parentchild interaction. In E.M. Hetherington (Ed.), P.H. Musen (series Ed.), Handbook of child psychology, 4, 1-101. New York: Wiley.

Manpower Group (2014). The talent shortage continues: How the ever changing role of HR can bridge the gap retrieved, May, 29th, 2018 from http://widget.weforun.org/nve-2015/chapter1.html

Meltzer, L. (2007). Executive function in education: From theory to practice. New York: The Guilford Press.

Miller, S., Heafner, T., \& Massey, D. (2009). High-school teachers' attempts to promote self- regulated learning: "I may learn from you, yet how do I do it?" Urban Review: Issues and Ideas in Public Education, 4, 121-140. https:// doi.org/10.1007/s11256-008-0100-3

Mills, J., Ayre, M., Hands, D., \& Carden, P. (2010). Learning about learning styles: Can it improve engineering education? Mountain Rise, 2(1) 1-16.

National Research Council. (2000). How people learn: Brain, mind, experience, and school. J. D. Bransford, A. L. Brown, \& R. R. Cocking (Eds.).Committee on developments in the science of learning and committee on learning Research and educational Practice. Washington, DC: National Academy Press.

National Research Council. (2005). How students learn: History, mathematics, and science in the classroom. Committee on How People Learn, a targeted report for teachers. M. S. Donovan \& J. D. Bransford (Eds.).Division of behavioral and social Sciences and education. Washington, DC: National Academy Press.

Ness, B. M., \& Middleton, M. J. (2011). A framework for implementing individualized self- regulated learning strategies in the classroom. Intervention in School and Clinic, 47(5), 267-275. New York: Basic Book. https://doi.org/10.1177/1053451211430120 
OECD (2013), OECD skills outlook 2013: First results from the survey of adult skills, OECD Publishing.

O'Donnell, A. M., \& Dansereau, D. F. (2000). Interactive effects of prior knowledge and material format on cooperative teaching. Journal of Experimental Education, 68, 101-118. https:// doi.org/10.1080/00220970009598497

Palincsar, A.S., \& A.L. Brown (1984) Reciprocal teaching of comprehension monitoring activities. Cognition and Instruction, 1 (2) 117-175 https://doi.org/10.1207/s1532690xci0102_1

Piaget, J. (1955). The language and thought of the child. New York: Meridian Books. https://doi.org/10.4324/9781315832128

Pintrich, P.R (2002). The role of metacognitive knowledge in learning, teaching, and $\begin{array}{llll}\text { assessing. Theory into } & \text { 219-225. }\end{array}$ https://doi.org/10.1207/s15430421tip4104_3

Pritchard, A. (2009). Ways of learning: learning theories and learning styles in the classroom (2nd ed.): David Fulton Publish. https:// doi.org/10.4324/9780203887240

Purdie, N., Carroll, A., \& Roche, L. (2004). Parenting and adolescent self-regulation. Journal of Adolescence, 27, 663-676. https://doi.org/10.1016/j.adolescence.2004.01.002

Puustinen, M., \& Pulkkinen, L. (2001). Models of self-regulated learning: A review. Scandinavian Journal of Educational Research, 5(3), 269-286.

Resnick, L.B (1987). Education and learning to think. Washington, D.C.: National Academy Press.

Resnick, B., \& Klopfer,L.E. (1989). Towards the thinking curriculum: Current cognitive research. ASCD Yearbook. Alexandria, VA: American Association for Curriculum Development.

Salomon, G. (Ed.). (1993). Distributed cognition. Psychological and educational considerations. Cambridge, UK: Cambridge University Press.

Schoenfeld, A.H (2016). Research in mathematics education. Review of Research in Education, 40 (1) 497-528. http:// doi.org/10.31040091732X16658650

Schraw,G.,\& Dennison,R.S. (1994).Assessing metacognitive awareness. Contemporary Educational Psychology, 19, 460-475. https://doi.org/10.1006/ceps.1994.1033

Schunk, D. H., \& Zimmerman, B. J. (1997). Social origins of self-regulatory competence. Educational Psychologist, 32(4), 195-208. https://doi.org/10.1207/s15326985ep3204_1

Schwartz, M. \& Fischer, K. W (2004). Building general knowledge and skill: cognition and microdevelopment in cience Learning. In A. Demetriou \& A. Raftopoulos, (Eds) Cognitive developmental change: Theories, models, and measurement, (pp. 157185), Cambridge: University Press, Cambridge, https:// doi.org/10.1017/cbo9780511489938.006

Shapiro, A. M. (2004). Prior knowledge must be included as a subject variable in learning outcomes Research. American Educational Research Journal, 41(1), 159-189. https://doi.org/10.3102/00028312041001159

Shaw, R, S. (2012). A study of the relationships among earning styles, participation types, and performance in programming language learning supported by online forums. Journal Computers and Education, 58 (1) 111-120 https:// doi $\underline{10.1016 / \text { j.compedu.2011.08.013 }}$ 
Simons, R. J., van der Linden, J., \& Duffy, T. (Eds.). (2000). New learning. Dordrecht, The Netherlands: Kluwer Academy Publishers.

Steinberg, L., Lamborn, S. D., Darling, N., Mounts, N. S., \& Dornbusch, S. M. (1994). Over- time changes in adjustment and competence among adolescents from authoritative, authoritarian, indulgent, and neglectful families. Child Development, 65(3), 754-770. https://doi.org/10.2307/1131416

Suina, J.H., \& L.B. Smolkin (1994). From natal culture to school culture to dominant society culture: Supporting transitions for Pueblo Indian students. In P.M. Greenfield \& R.R. Cocking (Eds). Cross-cultural roots of minority child development, (pp.115-130) Hillsdale, NJ: Erlbaum.

Tanner, K.D. (2012). Promoting student metacognition. CBE - Life Sciences Education, 11, 113-120. https:// doi.org/10.1187/cbe.12-03-0033

Tonks, S. M. \& Taboada, A. (2011). Self-regulatory training through elementary-school students' homework completion. In B.J. Zimmerman \& D.H. Schunk (Eds.), Handbook of self-regulation of learning and performance (pp. 87-101). New York: Routledge. https:// doi.org/10.4324/9780203839010.ch6

Tuana, H., Chinb, C., \& Shiehc, S. (2005). The development of a questionnaire to measure students' motivation towards science learning. International Journal of Science Education, 27(6), 639-654. https://doi.org/10.1080/0950069042000323737

Van der Steen, S., Steenbeek, H., Wielinski, J \& Van Geert, P.(2012). A comparison between young students with and without special needs on their understanding of scientific concepts, Education Research International, vol. 2012, pp. 1-12, 2012. https://doi.org/10.1155/2012/260403

Vigotsky, L.V (1962). Thought and language. Cambridge, MA. MIT Press.

Weinert, F. E., \& Helmke, A. (1998). The neglected role of individual differences in theoretical models of cognitive development. Learning and Instruction, 8, 309-323. https://doi.org/10.1016/s0959-4752(97)00024-8

Wellman, H.M. (1990). The Child's theory of mind. Cambridge, MA: MIT Press.

Winne, P. (1995). Inherent details in self-regulated learning. Educational Psychologist, 30(4), 173-187. https://doi.org/10.1207/s15326985ep3004_2

Woodcock, J (2017). Woodcock Johnson Test Guide.

Zimmerman, B. J. (1994). Dimensions of academic self-regulation: A conceptual framework for education. In D. H. Schunk \& B. J. Zimmerman (Eds.), Selfregulation of learning and performance: Issues and educational applications (pp. 321). Hillsdale, NJ: Lawrence Erlbaum.

Zimmerman, B. J. (1989). A social cognitive view of self-regulated academic learning. Journal of Educational Psychology, 81, 329-339. https://doi.org/10.1037//0022$\underline{0663.81 .3 .329}$

Zimmerman, B. J. (1998). Developing self-fulfilling cycles of academic regulation: An analysis of exemplary instructional models. In D. H. Schunk \& B. J. Zimmerman (Eds.), Self-regulated learning: From teaching to self-reflective practice (pp. 1-19). New York: The Guilford Press.

Zimmerman, B. J. (2001) Theories of self-regulated learning and academic achievement: An overview and analysis. In B. J. Zimmerman \& D. H. Schunk (Eds.), Selfregulated learning and academic achievement: Theoretical perspectives (2nd ed., pp. 138). New York: Lawrence Erlbaum Associates.

Zimmerman, B. J., \& Kitsantas, A. (2005). The hidden dimension of personal competence: Self-regulated learning and practice. In A.J. Elliot, C.S. Dweck, \& S. Carol (Eds.), 
Handbook of competence and motivation (pp. 509-526), New York: Guilford Publications.

Zimmerman, B.J., \& Martinez M.P. (1986). Development of a structured interview for assessing student use of self-regulated learning strategies. American Educational Research Journal 23(4) 614-628. https:// doi.org/10.3102/00028312023004614

Zimmerman, B. J., \& Risemberg, R. (1997). Self-regulatory dimensions of academic learning and motivation. In G. D. Phye (Ed.), Handbook of academic learning: Construction of knowledge (pp. 105-125). San Diego, CA: Academic Press. https://doi.org/10.1016/b978-012554255-5/50005-3 